Author(s): Haarahiltunen, Antti \& Väinölä, Hele \& Anttila, O. \& Yli-Koski, Marko

Title: $\quad$ Experimental and theoretical study of heterogeneous iron precipitation in silicon

Year: $\quad 2007$

Version: Final published version

Please cite the original version:

Haarahiltunen, Antti \& Väinölä, Hele \& Anttila, O. \& Yli-Koski, Marko. 2007. Experimental and theoretical study of heterogeneous iron precipitation in silicon. Journal of Applied Physics. P. 7. 0021-8979 (printed). DOI: 10.1063/1.2472271

Note: $\quad$ Copyright 2007 American Institute of Physics. This article may be downloaded for personal use only. Any other use requires prior permission of the author and the American Institute of Physics.

http://scitation.aip.org/content/aip/journal/jap

All material supplied via Aaltodoc is protected by copyright and other intellectual property rights, and duplication or sale of all or part of any of the repository collections is not permitted, except that material may be duplicated by you for your research use or educational purposes in electronic or print form. You must obtain permission for any other use. Electronic or print copies may not be offered, whether for sale or otherwise to anyone who is not an authorised user. 


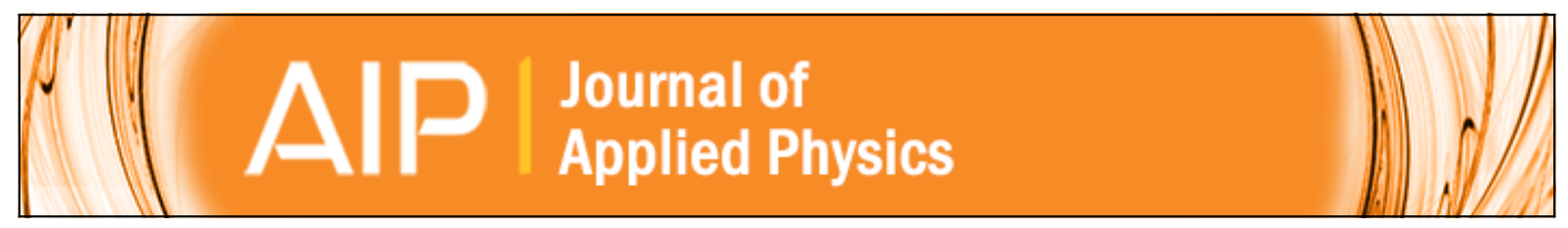

\section{Experimental and theoretical study of heterogeneous iron precipitation in silicon}

A. Haarahiltunen, H. Väinölä, O. Anttila, M. Yli-Koski, and J. Sinkkonen

Citation: Journal of Applied Physics 101, 043507 (2007); doi: 10.1063/1.2472271

View online: http://dx.doi.org/10.1063/1.2472271

View Table of Contents: http://scitation.aip.org/content/aip/journal/jap/101/4?ver=pdfcov

Published by the AIP Publishing

\section{Articles you may be interested in}

Modeling of heterogeneous precipitation of iron in silicon

Appl. Phys. Lett. 87, 151908 (2005); 10.1063/1.2099531

Oxygen precipitation in nitrogen doped Czochralski silicon wafers. I. Formation mechanisms of near-surface and bulk defects

J. Appl. Phys. 96, 3255 (2004); 10.1063/1.1773921

Copper precipitates in silicon: Precipitation, dissolution, and chemical state

J. Appl. Phys. 91, 6396 (2002); 10.1063/1.1471944

Thermal stability of copper precipitates in silicon

Appl. Phys. Lett. 77, 3598 (2000); 10.1063/1.1328769

Oxygen precipitation in silicon: Experimental studies and theoretical investigations within the classical theory of nucleation

J. Appl. Phys. 85, 8097 (1999); 10.1063/1.370648

You don't

still use this

cell phone

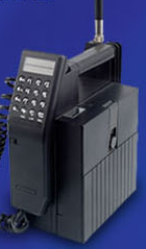

or this computer

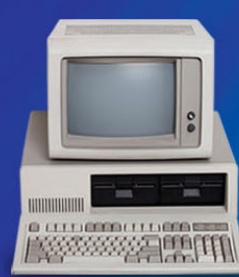

Why are you

still using an

AFM designed in the 80 's?
It is time to upgrade your AFM

Minimum \$20,000 trade-in discount for purchases before August 31st

Asylum Research is today's technology leader in AFM

dropmyoldAFM@oxinst.com

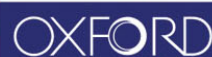




\title{
Experimental and theoretical study of heterogeneous iron precipitation in silicon
}

\author{
A. Haarahiltunen ${ }^{\text {a) }}$ and H. Väinölä \\ Helsinki University of Technology, P.O. Box 3500, FI-02015 TKK, Finland \\ O. Anttila \\ Okmetic Oyj, P.O. Box 44, FI-01301 Vantaa, Finland
}

M. Yli-Koski and J. Sinkkonen

Helsinki University of Technology, P.O. Box 3500, FI-02015 TKK, Finland

(Received 26 October 2006; accepted 21 December 2006; published online 20 February 2007)

\begin{abstract}
Heterogeneous iron precipitation in silicon was studied experimentally by measuring the gettering efficiency of oxide precipitate density of $1 \times 10^{10} \mathrm{~cm}^{-3}$. The wafers were contaminated with varying iron concentrations, and the gettering efficiency was studied using isothermal annealing in the temperature range from 300 to $780^{\circ} \mathrm{C}$. It was found that iron precipitation obeys the so-called s-curve behavior: if iron precipitation occurs, nearly all iron is gettered. For example, after $30 \mathrm{~min}$ annealing at $700{ }^{\circ} \mathrm{C}$, the highest initial iron concentration of $8 \times 10^{13} \mathrm{~cm}^{-3}$ drops to 3 $\times 10^{12} \mathrm{~cm}^{-3}$, where as two lower initial iron concentrations of $5 \times 10^{12}$ and $2 \times 10^{13} \mathrm{~cm}^{-3}$ remain nearly constant. This means that the level of supersaturation plays a significant role in the final gettering efficiency, and a rather high level of supersaturation is required before iron precipitation occurs at all. In addition, a model is presented for the growth and dissolution of iron precipitates at oxygen-related defects in silicon during thermal processing. The heterogeneous nucleation of iron is taken into account by special growth and dissolution rates, which are inserted into the Fokker-Planck equation. Comparison of simulated results to experimental ones proves that this model can be used to estimate internal gettering efficiency of iron under a variety of processing conditions. (C) 2007 American Institute of Physics. [DOI: 10.1063/1.2472271]
\end{abstract}

\section{INTRODUCTION}

Purity requirements of starting materials and cleanliness of the processes are ever increasing in the modern semiconductor technology. Internal gettering (IG), i.e., the capability of oxide precipitate related defects to capture impurities, is widely utilized in the integrated circuit industry to remove harmful metal contaminants from the device areas. However, a full understanding of the gettering mechanism has not been achieved so far. Better knowledge about behavior of transition metals and defect dynamics in silicon is essential in controlling the impurities by gettering. Only with increased understanding it is possible to create fully predictive models for transition metal behavior under different processing conditions, and eventually, to optimize the device yield.

One of the most troubling and common contaminant in silicon is iron. It diffuses relatively rapidly and it has deleterious effects on the device performance even when present in small concentrations. As experimental process optimization for impurity gettering is expensive and time consuming, several papers ${ }^{1-7}$ discuss modeling of iron gettering. In these papers, iron precipitation to oxide precipitates is usually modeled using Ham's law, ${ }^{8}$ and it is further assumed that all oxide precipitates are effective (active) gettering sites, i.e., each oxide precipitate contains iron precipitate(s). Indeed, it is experimentally confirmed that at very high supersaturation the iron precipitation can be described through Ham's law. ${ }^{1,9}$

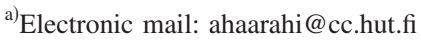

However, these simulations greatly overestimate the gettering efficiency in slowly cooled samples. ${ }^{10}$ A better agreement between simulations and experiments was achieved by using a significantly lower effective gettering site density compared with the oxide precipitate density. ${ }^{10}$ This means that the dynamics of nucleation of iron precipitates must be taken into account, and the number of effective gettering sites may be only a small portion ${ }^{1,11,12}$ of the total oxide precipitate density.

In Refs. 6 and 7 the nucleation is taken into consideration using a steaty-state nucleation rate, and it is shown that iron precipitation can then be simulated at low supersaturation level. However, it is difficult to handle the size distribution in the steady-state approach. The proper treatment of the size distribution is especially important as more complex processes than cooling or isothermal annealing are simulated. We have recently suggested a model for heterogeneous precipitation of iron in silicon, ${ }^{13}$ in which we use chemical rate equations (CREs) to calculate the size distribution of the iron precipitates and the residual dissolved iron concentration.

In this paper we demonstrate experimentally that iron precipitation produces similar s-curve behavior to what is typical, e.g., for oxygen precipitation. ${ }^{14,15}$ We propose a model for heterogeneous iron precipitation, in which we use growth and dissolution rates ${ }^{13}$ and the Fokker-Planck equation (FPE) to simulate the cluster evolution. We show that the proposed model can capture the effect of supersaturation to iron precipitation and explain the s-curve behavior. We 
also show that the proposed model can be used to simulate IG in various processing conditions reported in the literature.

\section{EXPERIMENT}

The silicon wafers used in the experiments were boron doped and their resistivities were about $30 \Omega \mathrm{cm}$. The oxygen content ${ }^{16}$ was 15 ppma. First, a 15 min dry oxidation (homogenization) at $1050{ }^{\circ} \mathrm{C}$ was performed, which was followed by low-high annealings $\left(6 \mathrm{~h} 650{ }^{\circ} \mathrm{C}+\right.$ slow ramp $+6 \mathrm{~h}$ $1100{ }^{\circ} \mathrm{C}$ ) to form oxide precipitates. The slow ramp was $0.5^{\circ} \mathrm{C} / \mathrm{min}$ from 650 to $800^{\circ} \mathrm{C}$, was $1{ }^{\circ} \mathrm{C} / \mathrm{min}$ from 800 to $900{ }^{\circ} \mathrm{C}$, and $2{ }^{\circ} \mathrm{C} / \mathrm{min}$ from 900 to $1100{ }^{\circ} \mathrm{C}$. The oxide layer was then removed and the wafers were contaminated in a $\mathrm{SC} 1$ solution with $30 \mathrm{ppb}$ iron added impurities. The wafers were divided into three separate groups. Each group was submitted to a different temperature, 760,850 , or $940{ }^{\circ} \mathrm{C}$, at which iron was driven in the wafers. The goal was to get three groups of wafers with different iron concentrations. After the indiffusion, the residual surface contamination was removed by etching the wafers in a $\mathrm{H}_{2} \mathrm{O}: \mathrm{HF}: \mathrm{H}_{2} \mathrm{O}_{2}$ (24:1:1) solution and by cleaning in a sequence of $\mathrm{SC} 1, \mathrm{SC} 2$, and $\mathrm{HF}$ dips. The wafers were then dry oxidized at $900{ }^{\circ} \mathrm{C}$ for $20 \mathrm{~min}$ to form an oxide layer of about $10 \mathrm{~nm}$. The initial iron concentrations were measured to be $5 \times 10^{12}, 2 \times 10^{13}$, and $8 \times 10^{13} \mathrm{~cm}^{-3}$, respectively. The initial iron concentrations were measured using deep level transient spectroscopy (DLTS) after a quench from indiffusion temperature.

The oxide precipitate density after low-high annealing was about $1 \times 10^{10} \mathrm{~cm}^{-3}$, as measured using optical microscopy after a selective Wright etch step. The homogeneity of oxygen precipitation was also checked with microwave detected photoconductive decay $(\mu$-PCD). The size of oxide precipitates measured by transmission electron microscopy (TEM) was about $80 \mathrm{~nm}$.

Before each gettering annealing, the wafers were annealed for $30 \mathrm{~min}$ at the indiffusion temperature to dissolve the possible iron nuclei that may have been formed during the temperature ramps ${ }^{17}$ after the oxidation annealing. The wafers were then cooled at a rate of $50{ }^{\circ} \mathrm{C} / \mathrm{min}$ to the gettering temperature, and the actual gettering annealing took $30 \mathrm{~min}$ at different temperatures $\left(300-800{ }^{\circ} \mathrm{C}\right)$. After the gettering annealing, the wafers were cooled to room temperature at a rate of $100{ }^{\circ} \mathrm{C} / \mathrm{min}$. In other words, the outline of the gettering annealing is as follows: $30 \mathrm{~min}$ dissolution annealing $\rightarrow$ cooling $\quad 50{ }^{\circ} \mathrm{C} / \mathrm{min} \rightarrow 30 \mathrm{~min} @ 200-800{ }^{\circ} \mathrm{C}$ $\rightarrow$ cooling $100{ }^{\circ} \mathrm{C} / \mathrm{min}$ to RT. It should be noted here that the cooling rates mentioned here are programed rates of furnace and actual cooling rates were not measured and they might deviate from programed rates. However, in these experiments we tried to maximize the cooling rates so that the gettering annealings, as much as possible, determine the iron precipitation behavior. The remaining interstitial iron concentration after gettering was measured using $\mu$-PCD. ${ }^{18,19}$ $\mu$-PCD measurement has been calibrated against DLTS, and the iron concentrations of individual sample were also checked by DLTS if the iron concentration was close to the detection limit of $\mu$-PCD. ${ }^{19}$

\section{MODEL FOR HETEROGENEOUS PRECIPITATION OF IRON}

The CRE can be solved using the selected grid point method $^{20}$ as we have done earlier in Ref. 13. This solution is rather time consuming. That is why we use here the FPE to simulate the evolution of the size distribution of iron precipitates

$$
\frac{\partial f(n, t)}{\partial t}=\frac{\partial}{\partial n}\left[-A(n, t) f(n, t)+B(n, t) \frac{\partial f(n, t)}{\partial n}\right],
$$

where $f(n, t)$ is the density of heterogeneous precipitation sites containing $n$ atoms of precipitated iron and

$$
\begin{aligned}
& A(n, t)=g(n, t)-d(n, t), \\
& B(n, t)=\frac{g(n, t)+d(n, t)}{2} .
\end{aligned}
$$

The growth and dissolution rates are $\mathrm{e}^{13}$

$$
g(n, t)=4 \pi r_{\mathrm{ox}} D C_{\mathrm{Fe}} \quad \text { and } d(n, t)=4 \pi r_{\mathrm{ox}} D C_{\mathrm{eq}},
$$

where $r_{\mathrm{ox}}$ is the average radius of the oxide precipitates (considered as an effective value if morphology is not spherical), $D$ is the diffusion constant of iron, $C_{\mathrm{Fe}}$ is the interstitial iron concentration, and $C_{\mathrm{eq}}$ is the equilibrium iron concentration at the interface of gettering site. We presume that the equilibrium iron concentration at the interface depends on the number of iron atoms precipitated to the gettering site and has the form ${ }^{13}$

$$
C_{\mathrm{eq}}=C_{\mathrm{Sol}} \exp \left(\frac{E_{a}}{k T n^{1 / 2}}\right),
$$

where $E_{a} / n^{1 / 2}$ describes the fact that iron has a higher chemical potential in a small cluster than in a large cluster and $C_{\text {Sol }}$ is the equilibrium concentration at the interface of a very large iron precipitate. $E_{a}$ is a fitting parameter which is related to surface energy and it also includes possible effects of $\operatorname{strain}^{21-23}$ and the morphology ${ }^{1}$ of oxide precipitates as well as the charge state ${ }^{24}$ of iron.

The practical numerical solution of the FPE, which is unconditionally stable and relatively larger time steps are allowed, is given in Ref. 25. The solution of the FPE requires boundary condition at size of 1 ,

$$
f(1, t)=P_{1} f(0, t) \exp \left[\frac{k T \ln \left(C_{\mathrm{Fe}} / C_{\mathrm{Sol}}\right)-2 E_{a}}{k T}\right],
$$

which is actually the size distribution function for a quasiequilibrium state in an ideal heterogeneous nucleation process adjusted with a fitting parameter $P_{1}{ }^{15}$ In the IG simulation,

$$
f(0, t)=N_{\text {ox }}-\int_{1}^{n_{\max }} f(n, t) d n
$$

is the density of such gettering sites that do not contain iron and $N_{\text {ox }}$ is the density of oxide precipitates. 


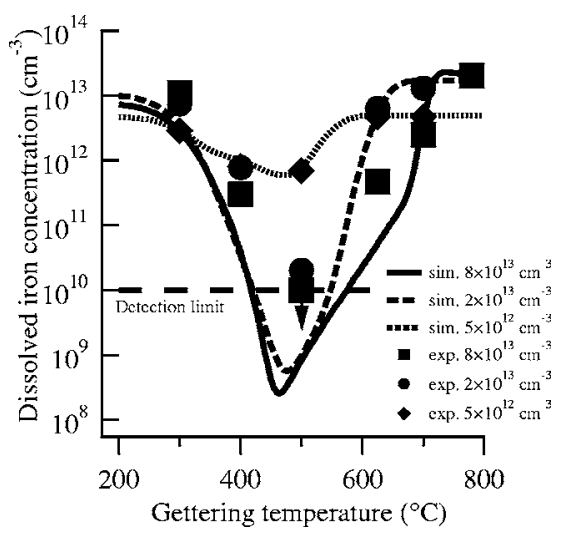

FIG. 1. Comparison of simulated (lines) and experimental results (symbols) of remaining dissolved iron concentration measured after $30 \mathrm{~min}$ of isothermal annealing. Initial iron concentrations were $8 \times 10^{13} \mathrm{~cm}^{-3}$ (square, solid line), $2 \times 10^{13} \mathrm{~cm}^{-3}$ (circle, dashed line), and $5 \times 10^{12} \mathrm{~cm}^{-3}$ (diamond, dotted line). The simulations include programed temperature ramps of the furnace.

\section{RESULTS AND DISCUSSION}

\section{A. Experimental and simulation}

The symbols in Fig. 1 show the experimental results. At $300{ }^{\circ} \mathrm{C}$, gettering is limited by diffusion, and almost no gettering takes place in any wafer. More interesting observations can be made at higher temperatures. The remaining dissolved iron concentration depends strongly on the initial iron concentration: the higher the initial iron concentration the less iron is measured after gettering. Note that at $500{ }^{\circ} \mathrm{C}$ the highest initial contamination level is gettered below our detection limit of $1 \times 10^{10} \mathrm{~cm}^{-3}$. Therefore, the level of supersaturation, $k T \ln \left(C_{\mathrm{Fe}} / C_{\mathrm{Sol}}\right)$, plays evidently a very significant role in the final gettering efficiency. The effect of supersaturation level is further supported by the observation that a rather high supersaturation is required before precipitation occurs at all. The supersaturation increases with lower temperature in all wafers, thus reducing the measured iron concentration as a function of temperature for temperatures above $450{ }^{\circ} \mathrm{C}$. In other words, iron must be highly supersaturated and mobile at the same time, and this will result in a certain optimum "processing window," where gettering is efficient. The optimum temperature depends on the initial iron concentration and the gettering time. The smaller the initial concentration, the lower the optimum temperature is. Notice that the wafer with the lowest initial iron concentration does not experience almost any gettering at any temperature. This is because the combination of high enough supersaturation together with high diffusivity is not reached at all.

The corresponding simulation results are shown by lines also in Fig. 1. In our simulations we use $C_{\mathrm{Sol}}=4.3$ $\times 10^{22} \exp (-2.10 \mathrm{eV} / \mathrm{kT}) \mathrm{cm}^{-3}$ (Ref. 26), $D=1 \times 10^{-3} \exp ($ $-0.67 \mathrm{eV} / \mathrm{kT}$ ) $\mathrm{cm}^{2} / \mathrm{s}$ (Ref. 27), and gettering site parameters $N_{\mathrm{ox}}=1 \times 10^{10} \mathrm{~cm}^{-3}$ and $r_{\mathrm{ox}}=40 \mathrm{~nm}$. The fitting parameters of the model were obtained using least square method and experimental results of $30 \mathrm{~min}$ isothermal annealing. Fitted parameters are $P_{1}=1 \times 10^{4}, E_{a}=\left(1.015 \times 10^{-4} T+0.8033\right) \mathrm{eV}$,

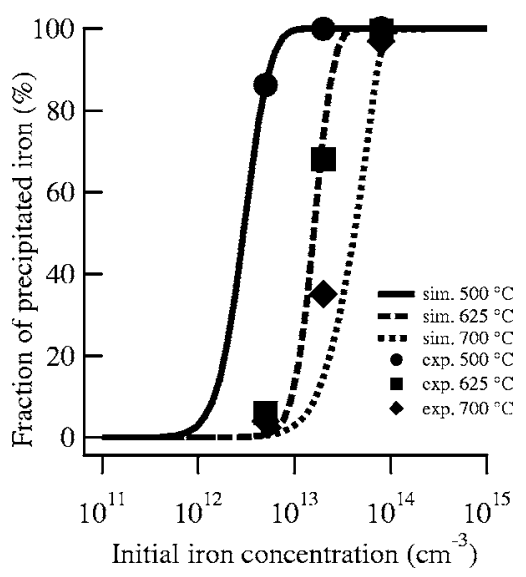

FIG. 2. Simulated and experimental s curve of iron precipitation at $700{ }^{\circ} \mathrm{C}$ (diamond, dotted line), $625^{\circ} \mathrm{C}$ (square, dashed line), and $500{ }^{\circ} \mathrm{C}$ (circle, solid line). The simulations include programed ramps of the furnace.

$T<773 \mathrm{~K}, \quad$ and $\quad E_{a}=\left(6.038 T \times 10^{-4} T+0.4150\right) \mathrm{eV}, \quad T$ $\geqslant 773 \mathrm{~K}$. With these parameters the experimental results can be fitted quite well, as shown in Fig. 1.

The results of Fig. 1 can be plotted as an s curve, which is typical, e.g., for oxygen precipitation. ${ }^{14,15}$ In Fig. 2 the results of gettering at temperatures 500,625 , and $700{ }^{\circ} \mathrm{C}$ are shown. Figure 2 clearly points out that as the initial supersaturation is above some threshold, nearly all iron will precipitate. This is well captured by the proposed model.

\section{B. Dependency on size and density of gettering site}

Takahashi $e$ e $a l .{ }^{21}$ reported interesting results that, for a fixed amount of precipitated oxygen, the gettering efficiency of large oxide precipitates was higher than the gettering efficiency of small oxide precipitates, in case of fast cooling at a rate of $25^{\circ} \mathrm{C} / \mathrm{s}$. In case of isothermal annealing at $190{ }^{\circ} \mathrm{C}$ the result was opposite: the gettering efficiency of small oxide precipitates was higher. ${ }^{21}$

We fitted the oxide precipitate densities and radii using the experimental results of isothermal annealing at $190{ }^{\circ} \mathrm{C}$ (Fig. 3) and using the sizes and areal densities reported by Takahashi et $a l^{21}{ }^{21}$ In the fitting we first fitted the density of the smallest (size of $10-15 \mathrm{~nm}$ ) oxide precipitate, as their size distribution is narrow, using average radius of $6.3 \mathrm{~nm}$. Then the other two oxide precipitate densities were calculated using the reported areal densities, and their average radii were obtained through a fit to the gettering results. The fitted average radii of 24 and $33 \mathrm{~nm}$ correspond to reported sizes of 25-35 and 40-80 nm, respectively. We set the initial iron concentration to $4.3 \times 10^{14} \mathrm{~cm}^{-3}$, which corresponds to $C_{\text {Sol }}$ value at the reported contamination temperature of $1050{ }^{\circ} \mathrm{C}$. The exponential decay as seen in Fig. 3 is commonly observed at high supersaturation levels ${ }^{1,9}$ and can be well explained using Ham's equation. ${ }^{8}$

The precipitation rate is always set by the $N_{\mathrm{ox}} r_{\text {ox }}$ product in Ham's equation and the experimental results at $190{ }^{\circ} \mathrm{C}$ support this (Fig. 3). However, Ham's equation cannot describe properly the fast cooling experiments of Takashi et al. ${ }^{21}$ Figure 4 shows simulated iron concentrations as functions of temperature, with the measured final concentrations taken from Ref. 21. The simulation agree relatively well with 


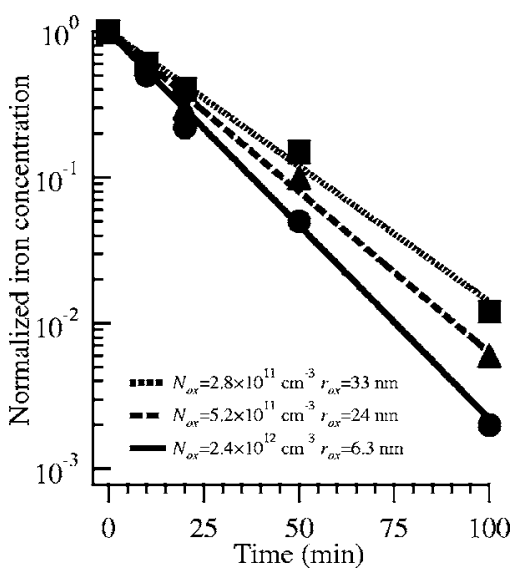

FIG. 3. Comparison of simulated (lines) and experimental results (symbols from Ref. 21) of remaining dissolved iron concentration measured during isothermal annealing at $190{ }^{\circ} \mathrm{C}$. The concentrations are normalized to the initial iron concentration, which was set to $4.3 \times 10^{14} \mathrm{~cm}^{-3}$ in the simulations. The fitted densities and average radii of oxide precipitates are shown in the legend.

experimental results, as the model suggests that larger oxide precipitates became effective gettering sites more easily than small ones simply due to the fact that growth and dissolution rates are proportional to the radii of precipitates. In reality, this may also be caused by strain field and extended defects that are often associated with large precipitates. ${ }^{21-23}$

We were not able to fit $N_{\text {ox }}$ and $r_{\text {ox }}$ values (Figs. 3 and 4) to a fixed total amount of precipitated oxygen even though it, measured using Fourier transform infrared spectroscopy (FTIR), was kept constant in experiments. ${ }^{21}$ Furthermore, we found out that for constant initial iron concentration, the model predicts $N_{\mathrm{ox}} r_{\mathrm{ox}}{ }^{2}$ dependency in gettering efficiency if nucleation limits the gettering efficiency. This result can be easily explained as nucleation produces a density of effective gettering sites $N_{\text {eff }} \sim N_{\text {ox }} r_{\text {ox }}$ [Eqs. (3) and (5)], and the final gettering efficiency (GE) after growth of iron precipitates depends on $N_{\text {eff }} r_{\text {ox }}$ product as

$$
\mathrm{GE}=100\left[1-\exp \left(-t_{G} 4 \pi D N_{\mathrm{eff}} r_{\mathrm{ox}}\right)\right],
$$

where $t_{G}$ is the length of the growth annealing.

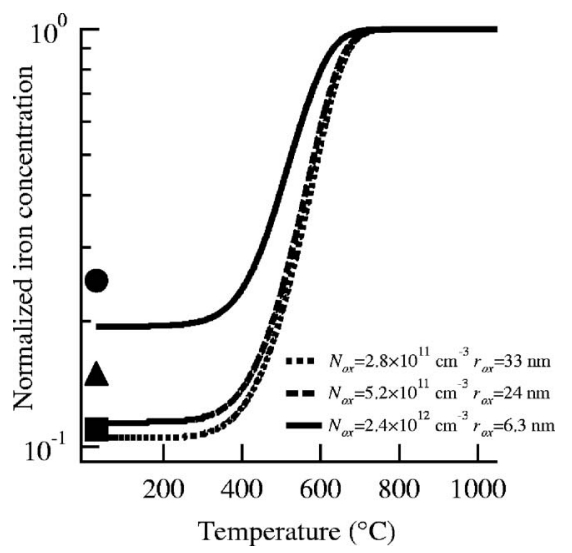

FIG. 4. Simulated interstitial iron concentrations during fast cooling (about $25 \mathrm{~K} / \mathrm{s})$. The initial iron concentration was $4.3 \times 10^{14} \mathrm{~cm}^{-3}$. The densities and average radii of oxide precipitates used in the simulations are shown in the legend. The experimental results (marked with symbols) are from Ref. 21.

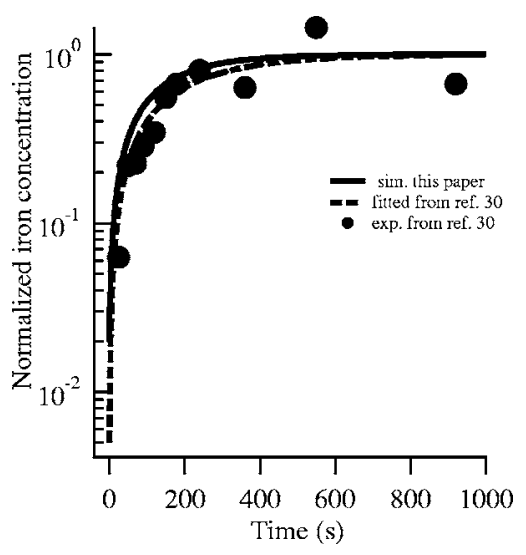

FIG. 5. Simulated (solid line) and experimental (circle) results show dissolved iron concentration vs time in dissolution annealing at $800{ }^{\circ} \mathrm{C}$, after iron had been gettered to oxide precipitates. The experimental results are from Ref. 30 .

Ogushi et al. $^{28}$ reported that gettering efficiency of iron correlates with total volume of oxide precipitates, which is clearly in disagreement with results of Takashi et al. ${ }^{21}$ however, the contamination level and gettering technique were different. Ogushi et al. ${ }^{28}$ used initial contamination level of about $1 \times 10^{12} \mathrm{~cm}^{-3}$, and the gettering was done in a long isothermal annealing after quenching to room temperature. This means that the final gettering efficiency was determined by iron nucleation during the ramp to room temperature and ramp up to gettering temperature.

\section{Dissolution of iron precipitates}

In addition to the gettering behavior, the thermal stability of iron precipitates is of interest for process simulations. The thermal stability of internally gettered iron has been studied by many authors, ${ }^{23,29,30}$ and it is known that after a sufficiently long high temperature annealing iron will be completely dissolved. Zhang et al. $^{30}$ studied the dissolution process in more detail using wafers with an oxide precipitate density of $5 \times 10^{9} \mathrm{~cm}^{-3}$, and the average radius was estimated to be $88 \mathrm{~nm}$ from decrease in the interstitial oxygen concentration. They contaminated samples to a level of about $1 \times 10^{14} \mathrm{~cm}^{-3}$ at $950{ }^{\circ} \mathrm{C}$. After that, the gettering was performed by cooling samples down to $700{ }^{\circ} \mathrm{C}$ at rate of $14{ }^{\circ} \mathrm{C} / \mathrm{min}$. The samples were kept at $700{ }^{\circ} \mathrm{C}$ for $30 \mathrm{~min}$ and then cooled to $450{ }^{\circ} \mathrm{C}$ at a rate of about $8^{\circ} \mathrm{C} / \mathrm{min}$. The final ungettered iron concentration was $5 \times 10^{10} \mathrm{~cm}^{-3}$. Iron dissolution was then studied at temperatures between 750 and $900{ }^{\circ} \mathrm{C}$.

In the simulation, we used initial iron concentration of $9.6 \times 10^{13} \mathrm{~cm}^{-3}$, which is the $C_{\text {Sol }}$ value at the contamination temperature of $950^{\circ} \mathrm{C}$. The simulation gives the remaining dissolved iron concentration of $1.2 \times 10^{11} \mathrm{~cm}^{-3}$, a value that is reasonably close to the measured value of $5 \times 10^{10} \mathrm{~cm}^{-3}$.

Figure 5 compares the simulated and experimental ${ }^{30}$ results of dissolution of gettered iron at $800{ }^{\circ} \mathrm{C}$. The simulated and experimental results agree quite well and the simulation gives an effective gettering site density of $9.5 \times 10^{7} \mathrm{~cm}^{-3}$. The dissolution time constant calculated using this effective gettering site density is $132 \mathrm{~s}$, whereas fitted time constant is 
$198 \pm 83$ s. ${ }^{30}$ Actually, calculated time constants deviated significantly only at $750{ }^{\circ} \mathrm{C}$, compared with the experimental, fitted dissolution time constants. ${ }^{30}$ This means that the simulation of iron precipitation and dissolution can be performed consistently using the same model, with no need to use a dissolution barrier proposed by Zhang et al. ${ }^{30}$

\section{Gettering sites}

One of the questions about IG is the type of defect, induced by oxygen precipitation, which is mainly responsible for iron precipitation. In the present model one can easily use different parameters for different types of defects: dislocations, stacking faults, and oxide precipitates. However, these parameters are hard to determine experimentally and this obviously makes the model less robust. Graff et al. ${ }^{31}$ stated that the IG of iron is mainly due to the presence of bulk stacking faults, and it does not depend on the density of oxide precipitates. On the other hand, they also stated that in many cases the density and size of oxide precipitates correlate with the existence of the bulk stacking faults.

Shen et $a l^{32,33}$ studied the precipitation of copper and iron to dislocations ${ }^{32}$ in floating-zone grown silicon and iron precipitation to bulk stacking faults, ${ }^{33}$ using different cooling rates. They reported that, after slow cooling, only some of the gettering sites are decorated by metals, whereas after fast cooling all of the gettering sites are decorated. These results can be easily reproduced in our simulations. During slow cooling the excess contamination is consumed by growth of existing metal precipitates and further nucleation, i.e., generation of new effective precipitation sites, is suppressed due to low supersaturation. On the other hand, during fast cooling the supersaturation remains high and nearly all possible precipitation sites become effective. Interestingly, Shen et $a l{ }^{32,33}$ explained their results in a similar manner.

As discussed previously, it seems that reasonably accurate modeling can be performed using the total defect density and some effective radius. How then should the total density and the effective radius be determined for simulation of iron IG? In this paper we use defect etching for density measurements and TEM to estimate the size of precipitation site. The size could be also estimated from oxygen loss as shown by analyzing the results of Zhang et $a l^{30}$ If either density or radius is known, then the other can be determined from a low temperature of $200{ }^{\circ} \mathrm{C}$ gettering test at a contamination level higher than $1 \times 10^{13} \mathrm{~cm}^{-3}$, just as we have done in simulation of the results of Takahashi et al. ${ }^{21}$ The model parameters can also be taken from any experimentally confirmed oxygen precipitation simulator.

\section{E. Precipitation of nickel and copper}

In the literature ${ }^{34-36}$ it is speculated that heterogeneous precipitations of iron, copper, and nickel in the presence of oxide precipitates and extended defects may be different from each other. This speculation is supported by the fact that the getterings of copper and nickel cannot be explained by Ham's equation ${ }^{35,36}$ which can be used for iron at sufficiently high supersaturation. We expect that the model presented here can easily be extended to copper and nickel pre- cipitation, if the experimental results ${ }^{35,36}$ are explained taking nucleation into account too, rather than through reaction limited precipitation only. Then the density of effective precipitation sites will be significantly smaller than the density of oxide precipitates. Note that in our model the gettering efficiency has the experimentally observed ${ }^{35,36} N_{\text {ox }} r_{\text {ox }}{ }^{2}$ dependency. Isomae et $a l .{ }^{37}$ also reported that the gettering efficiency of copper depends on the initial copper contamination level, which is naturally included in our model.

\section{CONCLUSIONS}

The experimental results of iron gettering in silicon by oxide precipitates and related defects revealed that rather high supersaturation is needed before nucleation of iron precipitates can take place. After nucleation the iron precipitation is fast due to relatively fast diffusion of iron. We proposed a model for heterogeneous iron precipitation, in which we use the FPE to simulate the cluster time evolution. Experimental results were used to find values for fitting parameters for the model. It was shown, comparing experimental results of Takahashi et al. ${ }^{21}$ to our simulations, that the model captures the effect of oxide precipitate radius and density to iron gettering. We were also able to simulate the gettering-dissolution experiment, reported by Zhang et al., ${ }^{30}$ in a consistent manner using the same model. Furthermore, the model can easily be expanded for precipitation of copper and nickel.

\section{ACKNOWLEDGMENTS}

The authors acknowledge the financial support from the Finnish National Technology Agency, Academy of Finland, Okmetic Oyj, Micro Analog Systems Oy, and VTI Technologies Oy. The use of TEM and quenching facilities at Lawrence Berkeley National Laboratories is acknowledged.

${ }^{1}$ H. Hieslmair, A. A. Istratov, S. A. McHugo, C. Flink, T. Heiser, and E. R. Weber, Appl. Phys. Lett. 72, 1460 (1998).

${ }^{2}$ H. Hieslmair, S. Balasubramanian, A. A. Istratov, and E. R. Weber, Semicond. Sci. Technol. 16, 567 (2001).

${ }^{3}$ A. L. Smith, K. Wada, and L. C. Kimerling, J. Electrochem. Soc. 147, $1154(2000)$.

${ }^{4}$ T. Y. Tan, R. Gafiteanu, S. M. Joshi, and U. Gösele, in Semiconductor Silicon 1998, edited by H. Huff, U. Gösele, and H. Tsuya (The Electrochemical Society, Pennington, NJ, 1998), p. 1050.

${ }^{5}$ H. Hieslmaier, A. A. Istratov, and E. R. Weber, Semicond. Sci. Technol. 13, 1401 (1998).

${ }^{6} \mathrm{~K}$. Nakamura and J. Tomioka, in Proceedings of The Electrochemical Society Spring 2006 Meeting, Denver, CO, edited by H. Huff, L. Fabry, D. Gilles, U. Goesele, T. Hattori, W. Huber, S. Ikeda, H. Iwai, P. Packan, H. Richter, M. Rodder, E. Weber, and R. Wise (The Electrochemical Society, Pennington, NJ, 2006), pp. 275-286.

${ }^{7}$ P. Geranzani, M. Pagani, C. Pello, and G. Borionetti, Solid State Phenom. 82-84, 381 (2002).

${ }^{8}$ F. S. Ham, J. Phys. Chem. Solids 6, 335 (1958).

${ }^{9}$ D. Gilles, E. R. Weber, and S. Hahn, Phys. Rev. Lett. 64, 196 (1990).

${ }^{10}$ A. Haarahiltunen, M. Yli-Koski, H. Väinölä, M. Palokangas, E. Saarnilehto, and J. Sinkkonen, Phys. Scr., T T114, 88 (2004).

${ }^{11}$ R. J. Falster, G. R. Fisher, and G. Ferrero, Appl. Phys. Lett. 59, 809 (1991).

${ }^{12} \mathrm{R}$. Falster, in Device Manu Proceedings of the Satellite Symposium to ESSDERC 93, Grenoble, France, edited by B. O. Kolbesen, C. Claeys, P. Stallhofer, and F. Tardif (The Electrochemical Society, Pennington, NJ, 1993), pp. 149-169.

${ }^{13}$ A. Haarahiltunen, H. Väinölä, O. Anttila, E. Saarnilehto, M. Yli-Koski, J. 
Storgårds, and J. Sinkkonen, Appl. Phys. Lett. 87, 151908 (2005).

${ }^{14}$ A. Borghesi, B. Pivac, A. Sassella, and A. Stella, J. Appl. Phys. 77, 4169 (1995).

${ }^{15}$ H. Takeno, T. Otogawa, and Y. Kitaqawara, J. Electrochem. Soc. 144 4340 (1997).

${ }^{16}$ ASTM F121-83.

${ }^{17}$ H. Väinölä, A. Haarahiltunen, M. Yli-Koski, E. Saarnilehto, and J. Sinkkonen, in Proceedings of The Electrochemical Society Fall 2004 Meeting, Honolulu, HA, edited by C. L. Claeys, M. Watanabe, R. Falster, and P. Stallhofer (The Electrochemical Society, Pennington, NJ, 2004), pp. $160-164$.

${ }^{18}$ A. Kempf, P. Blöchl, A. Huber, L. Fabry, and L. Meinecke, in Recombination Lifetime Measurements in Silicon, edited by D. C. Gupta, F. R. Bacher, and W. M. Hughes (ASTM, West Conshohocken, 1998), p. 259.

${ }^{19}$ A. Haarahiltunen, H. Väinölä, M. Yli-Koski, E. Saarnilehto, and J Sinkkonen, in Proceedings of The Electrochemical Society Fall 2004 Meeting, Honolulu, HA, edited by C. L. Claeys, M. Watanabe, R. Falster, and P. Stallhofer (The Electrochemical Society, Pennington, NJ, 2004), pp. 135-145.

${ }^{20}$ S. Kobayashi, J. Cryst. Growth 174, 163 (1997).

${ }^{21}$ H. Takahashi, H. Yamada-Kaneta, and M. Suezawa, Jpn. J. Appl. Phys., Part 1 37, 1689 (1998).

${ }^{22}$ J. Vanhellemont and C. Claeys, Mater. Sci. Forum 38, 171 (1989).

${ }^{23}$ S. A. McHugo, E. R. Weber, M. Mizuno, and F. G. Kirscht, Appl. Phys. Lett. 66, 2840 (1995).
${ }^{24}$ A. Mesli, T. Heiser, N. Amroun, and P. Siffert, Appl. Phys. Lett. 57, 1898 (1990).

${ }^{25}$ J. S. Chang, and G. Cooper, J. Comput. Phys. 6, 1 (1970).

${ }^{26}$ M. Aoki, A. Hara, and A. Ohsawa, J. Appl. Phys. 72, 895 (1992).

${ }^{27}$ A. A. Istratov, H. Hieslmair, and E. R. Weber, Appl. Phys. A: Mater. Sci. Process. A69, 13 (1999)

${ }^{28}$ S. Ogushi, S. Sadamitsu, K. Marsden, Y. Koike, and M. Sano, Jpn. J. Appl. Phys., Part 1 36, 6601 (1997).

${ }^{29}$ M. Aoki and A. Hara, J. Appl. Phys. 74, 1440 (1993).

${ }^{30}$ P. Zhang, H. Väinölä, A. A. Istratov, and E. R. Weber, Physica B 340-342, 1050 (2003).

${ }^{31}$ K. Graff, H. A. Hefner, and W. Hennerici, J. Electrochem. Soc. 135, 952 (1988).

${ }^{32}$ B. Shen, T. Sekiguchi, R. Zhang, Y. S. Shi, H. Shi, K. Yang, Y. Zheng, and K. Sumino, Jpn. J. Appl. Phys., Part 1 35, 3301 (1996).

${ }^{33}$ B. Shen et al., Appl. Phys. Lett. 70, 1876 (1997).

${ }^{34}$ A. A. Istratov, W. Huber, and E. R. Weber, J. Electrochem. Soc. 150, G244 (2003).

${ }^{35}$ K. Sueoka, M. Akatsuka, M. Yonemura, S. Sadamitsu, E. Asayama, T. Ono, Y. Koike, and H. Katahama, Solid State Phenom. 69-70, 63 (1999).

${ }^{36}$ R. Hoelzl, M. Blietz, L. Fabry, and R. Schmolke, in Semiconductor Silicon/2002, edited by H. R. Huff, L. Fabry, and S. Kishino (The Electrochemical Society, Pennington, NJ, 2002), pp. 608.

${ }^{37}$ S. Isomae, H. Ishida, Toshihiko, and K. Hozawa, J. Electrochem. Soc. 149, G343 (2002). 